\title{
Characterization of Corydalis (Papaveraceae s. l.) and Dioscorea (Dioscoreaceae) Species: 1. Root Anatomical Characters
}

\author{
Sophia Wan-Pyo Hong ${ }^{1}$ \\ ${ }^{1}$ Department of Pharmacy, Seoul National University, Seoul, South Korea \\ Correspondence: Sophia Wan-Pyo Hong, Natural Products Research Institute, Department of Pharmacy, Seoul \\ National University, Seoul 151-742, South Korea. Tel: 82-010-2806-7925. E-mail: sophiw08@gmail.com
}

Received: March 28, 2012 Accepted: April 11, 2012 Online Published: May 31, 2012

doi:10.5539/ijb.v4n3p1 URL: http://dx.doi.org/10.5539/ijb.v4n3p1

\begin{abstract}
Resin embedding methodology was evaluated for authentic herbal medicinal identification using tubers or rhizomes of Corydalis and Dioscorea in the current study. Dealing with hard herbal drug materials for anatomical works can be challenging, but using the resin embedding approach makes easier to dissect the herbal drugs. Corydalis and Dioscorea tubers are secondary organs considering the fact that they have main roots as well as the tubers or rhizomes. The tuber anatomical characters are not complicated; however, the characteristic anatomical features can be useful as identification tools for those well-known Oriental herbal medicines.
\end{abstract}

Keywords: Corydalis, Dioscorea, resin embedding, herbal medicines, identification

\section{Introduction}

\subsection{Need for Authentic Identification of Herbal Drugs}

The compilation of data about plants and their active ingredients (Dahanukar et al., 2000) is an important aspect of pharmacognosy. Many studies in this field relate to the analysis of chemical components from the root or whole herbal drug extracts (Tsai et al., 2004). However, fragments or powder, or dried roots, or other reproductive (fruits and seeds) and vegetative (leaves and stems) organs can be subjected to microscopic examinations (Serrano et al., 2010; Sahoo \& Swain, 2011) for proper and standardized herbal drugs using Histology (Serrano et al., 2010).

\subsection{Examples of Herbal Drug Mis-identifications}

The global use of oriental herbal drugs is increasing, and some of these herbal drugs have been confused with other common plants, threatening lives (Zhao et al., 2007; Ahmad et al., 2009; Kiran et al., 2010; Sultana et al., 2011). Misidentification of authentic herbal drugs has been a problem worldwide, for instance, four different species of Argemone, Cnicus, Solanum, and Fagonia have been claimed as the same medicine in the local markets in Parkistan (having the same local name: "Kiandari”, Zafar et al., 2010). In the case of Valerian roots ("Balchur"), two different species, Valeriana wallichiil DC. (Valeriniaceae) and Acorus calamus L. (Araceae), have been marketed commercially in Africa under the same local trade name (Ahmad et al., 2009).

\subsection{Histology as an Examination Tool}

Thus proper authentication of medicinal species is essential and histology has been regarded as an inexpensive and efficient (rapid) tool for herbal drug examinations (Serrano et al., 2010). DNA barcoding is a new and major technique for identification of angiosperm species, including herbal drugs (Guo et al., 2011; Li et al., 2011), but evaluation of a few DNA barcoding genes (e.g. ITS, trnH-psbA, rbcL, matK, Guo et al., 2011; Li et al., 2011) is not adequate proof of authenticity for drugs intended for human consumption unless supported by details of anatomical characteristics of dried roots, seeds, or fruits. Anatomical methods such as resin-embedding-based histology may be employed as robust supplementary tools for this purpose.

Plant anatomy studies of fresh materials have played an important historical role in identifying and classifying medicinal plants (Endress et al., 2000; Keshavarzi et al., 2011). However, due to the technical difficulty of dissecting hardened materials, the anatomical approach ( $\mathrm{Li}$ et al., 2011) has had limited application to herbal medicines. A resin-embedding method based on a glycol methacrylate (GMA) hydrophilic historesin has been used for dissecting these materials (Harris et al., 1992). The method was recommended for establishing 
anatomical properties for the identification of commercial herbal drug specimens. Comparing to the traditional wax-embedding method (Serrano et al., 2010), this GMA-based resin embedding approach is superior in terms of its efficiency by the fact that the resin does not need to be removed by adding many more steps (longer time for the processing). In the current work, the histology of root and rhizome materials of Corydalis and Dioscorea has been examined in order to establish whether high quality diagnostic characteristics could be established.

\subsection{Herbal Drugs Dioscorea and Corydalis}

Dioscorea is included in the monocot family Dioscoreaceae (Blunden et al., 1971) and its rhizomes have been used for treating a wide range of conditions including allergy, dermopathy, some cancers, diabetes mellitus, inflammation, lipoperoxidation, renal infections, and rheumatoid arthritis (Tewtrakul \& Itharat, 2006; Wang et al., 2007; Zhang et al., 2009; Zhu et al., 2010; Ghosh et al., 2012). The dicot genus Corydalis belongs to the poppy family Papaveraceae s.l. (Sagare et al., 2000; Kundu, 2008). About 300 species of Corydalis (Lidén, 1986; Lidén, 1995; Sagare et al., 2000) are found in warm areas of Asia, North and South Americas, and New Zealand (Sagare et al., 2000; Kundu, 2008). A range of pharmacologically active alkaloids may be isolated from Corydalis species (Martin \& Ortiz, 1963; Sagare et al., 2000). The tissues of some contain sapogenin precursors of cortisone and other steroids (Martin \& Ortiz, 1963), and dried tubers of Corydalis have been used for treatments of hypersensitivity, arrhythmia, dysmenorrhea, dyspepsia, rheumatism, and ulcers, etc. (Sagare et al., 2000; Wu et al., 2007; Henkes et al., 2011; Ji et al., 2012).

The characteristics of cultivated tubers of Corydalis were reported by Khodorova et al. (2010). The authors used resin for embedding the fresh materials. Leaf and stem anatomical characters of Dioscorea sylvatica Eckl. have been reported previously using a wax embedding method and the status of $D$. sylvatica revised to a subspecies (Blunden et al., 1971). Two species of Dioscorea, D. floribunda and D. spiculiflora, have been subjects for tuber anatomy studies (Martin \& Ortiz, 1963).

Using anatomical or histological characters for identifying herbal drugs has not been uncommon, particularly in traditional Chinese medicine (Zhao, 2010). The Technovit 7100 resin-embedding method (http://www.kulzer-technik.de) has not been commonly used for herbal drug identification so far. Therefore, in the current study the Technovit 7100 resin embedding technique for dissecting herbal medicine root materials was further investigated to establish whether the approach could be useful for herbal drugs.

\section{Method}

\subsection{Sample Collection}

Details of the plant materials used for this study are shown in Table 1. All specimens were collected in local markets in the Peoples' Republic of China. The voucher specimens are kept in the Natural Product Research Institute (NPRI) located at Seoul National University, Korea.

\subsection{Resin Embedding and Light Microscopy}

The samples were treated with $10 \% \mathrm{NH}_{3}$ solution (McLean, 1916), and stored long-term in $50 \%$ ethanol if necessary. After the pre-treatment, the samples were dehydrated in sequential $t$-butanol-water mixtures $(10 \%$, $20 \%, 35 \%, 55 \%$ and $75 \% t$-butanol in water) for a minimum of 12 hours at each stage. $t$-Butanol $(100 \%)$ was employed for the final dehydration step before infiltration with Technovit 7100 resin (Kulzer GmbH, Germany). During the pre-infiltration and infiltration steps, the samples were treated with ethanol: Technovit 7100 mixtures (75:25, 50:50 and 25:75 in sequence) followed by immersion in 100\% resin, for a minimum of 8 hours at each stage. The samples were attached to Histoblocks (Kulzer GmbH, Germany) with Technovit 3040. Finally, $3-5$ $\mu \mathrm{m}$ thick tissue sections were made using a manual rotary microtome (Reichert Jung Co., Germany). The sections were stained using $0.1 \%$ Toluidine Blue O dye (O'Brien et al., 1964). Images were obtained with a digital camera (DPx26, Olympus) attached to a light microscope (BX-50, Olympus).

\section{Results}

Cross sections of Corydalis and Dioscorea tubers are shown in Figures 1 to 6. It may be seen that Corydalis tubers consist of tissues including xylem, storage parenchyma cells, cortex, and cork layers. In the two Dioscorea taxa, the fundamental internal structures were similar (Figures 5 and 6). The individual descriptions are given below.

\subsection{Corydalis sp.}

Young tubers branch out of older ones (Figures $1 \mathrm{~d}$ and $4 \mathrm{a}$ ). The xylem systems in Corydalis sp. tubers are not complicated, with small and inconspicuous groups of xylems (Figures $1 \mathrm{~d}, 2 \mathrm{i}-2 . \mathrm{j}$, $4 \mathrm{~d}$ and $4 \mathrm{f}$ ). This is a consequence of their status as secondary roots. The inconspicuous vascular bundle system is distributed sparsely 
throughout the cortex (Figures 1d, 2i - 2j). Starch grains in the storage parenchyma cells are shaped like an elongated oval (Figures 1 and 3). The starch grains are relatively smaller than those of either Dioscorea species (Figure 1). The cork layers are also developed relatively weakly and are composed of 3 - 4 layers of periderm and cork layers (Figures 1f, 2k and 3e).
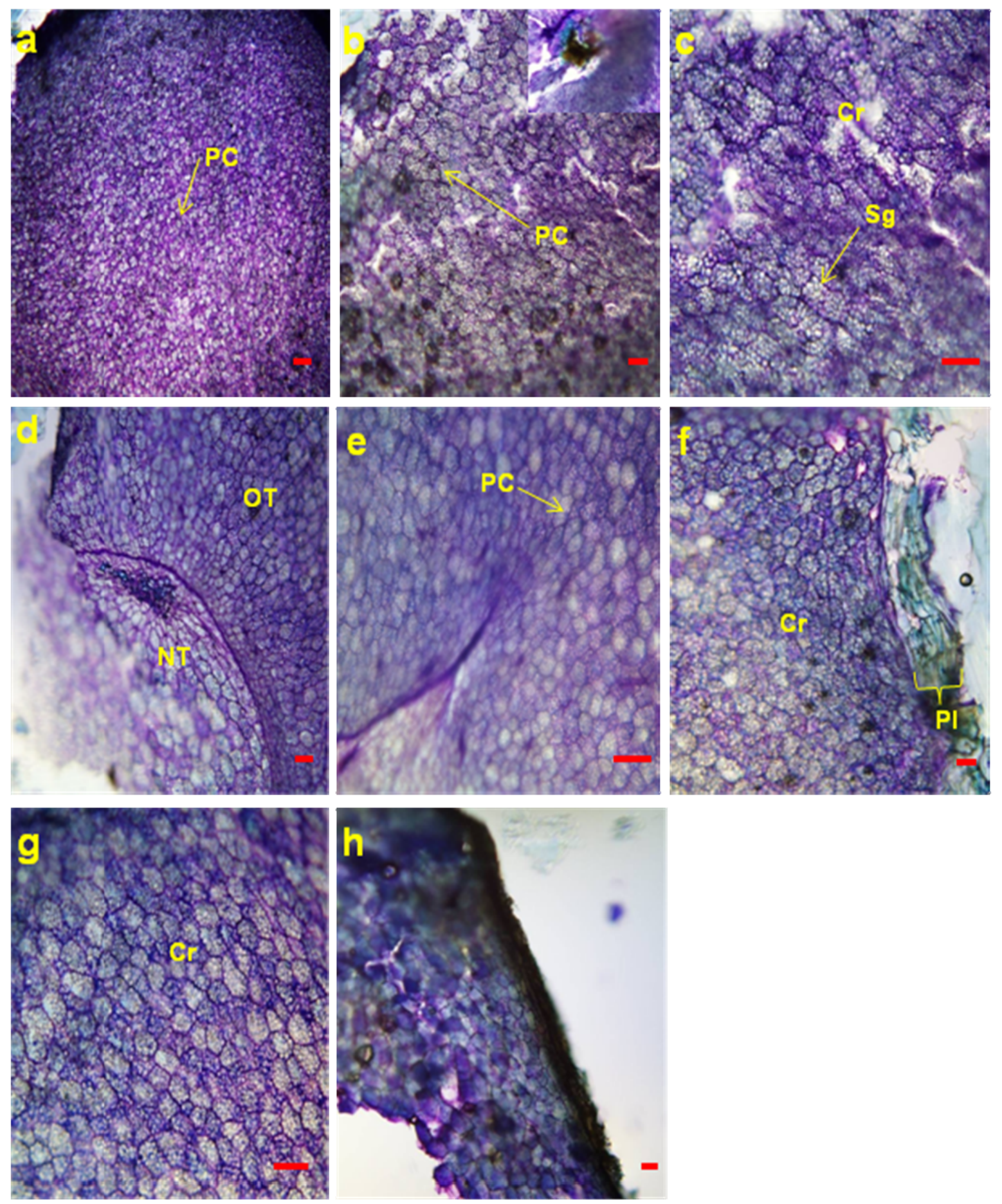

Figure 1. Cross sections of Corydalis ternate Nakai samples CT069, CT072 and CT073

Sample, magnification and scale bar length are 1a: CT069, x40, $250 \mu \mathrm{m}$; 1b: CT069, x100, $100 \mu \mathrm{m}$; 1c: CT069, x200, $50 \mu \mathrm{m}$; 1d: CT072, x40, $250 \mu \mathrm{m}$; 1e: CT072, x200, $50 \mu \mathrm{m}$; 1f: CT072, x100, $100 \mu \mathrm{m}$; 1g: CT072, x200, $50 \mu \mathrm{m}$; and 1h: CT073, x100, $100 \mu \mathrm{m}$. Symbols: PC, Parenchyma Cells; Cr, Cortex; Sg, Starch Granules; NT, New Tuber; OT, Old Tuber; Pl, Peridermal Layers. 

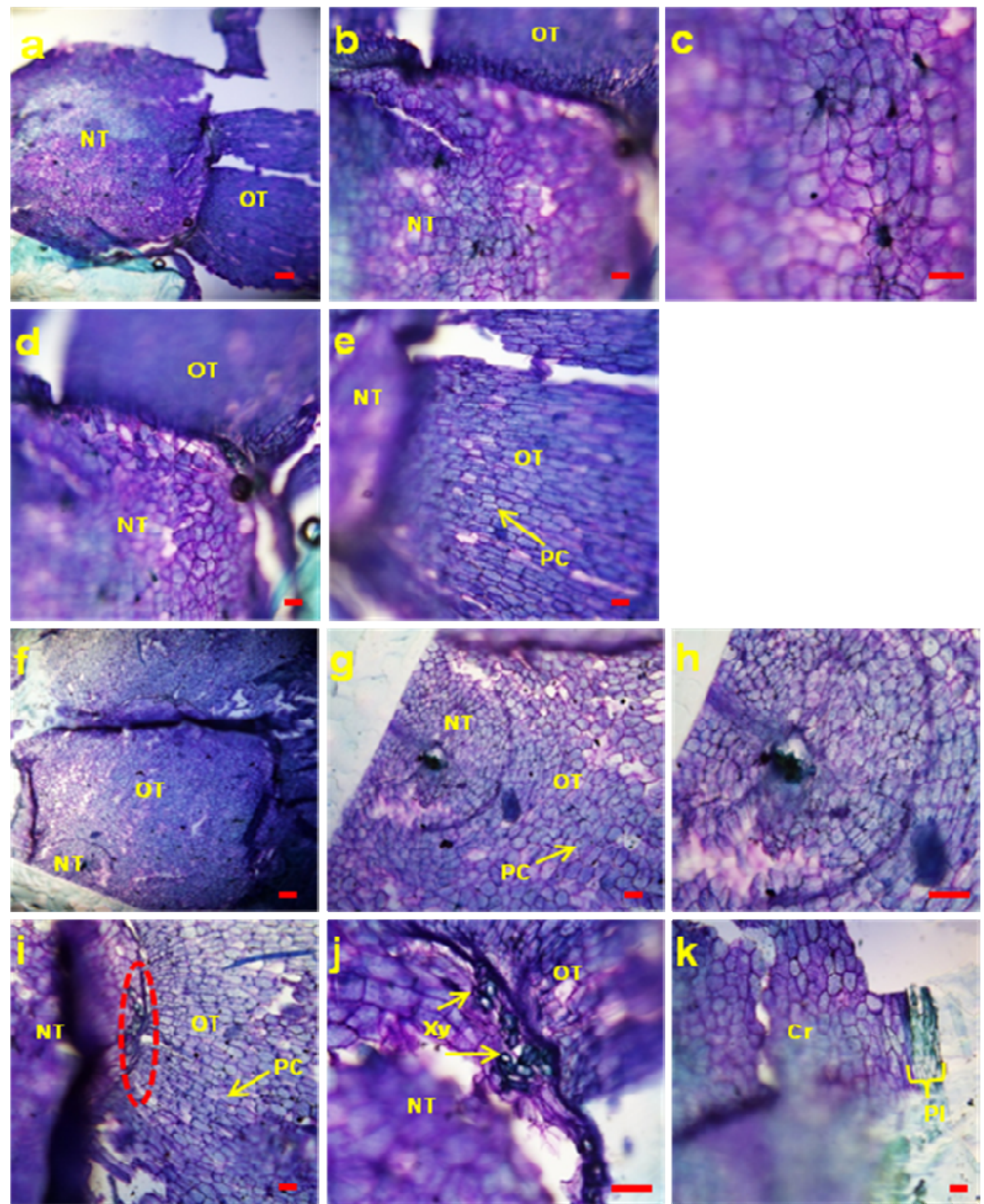

Figure 2. Cross sections of Corydalis ternate Nakai sample CT075

Magnification and scale bar length are 2a and 2f: x40, $100 \mu \mathrm{m} ; 2 \mathrm{~b}, 2 \mathrm{~d}, 2 \mathrm{e}, 2 \mathrm{~g}, 2 \mathrm{i}$ and 2k: x100, $100 \mu \mathrm{m} ; 2 \mathrm{c}, 2 \mathrm{~h}$ and 2j: x200, $50 \mu \mathrm{m}$. Symbols: PC, Parenchyma Cells; Cr, Cortex; Sg, Starch Granules; NT, New Tuber; OT, Old Tuber; Xy, Xylem; Pl, Peridermal Layers. 

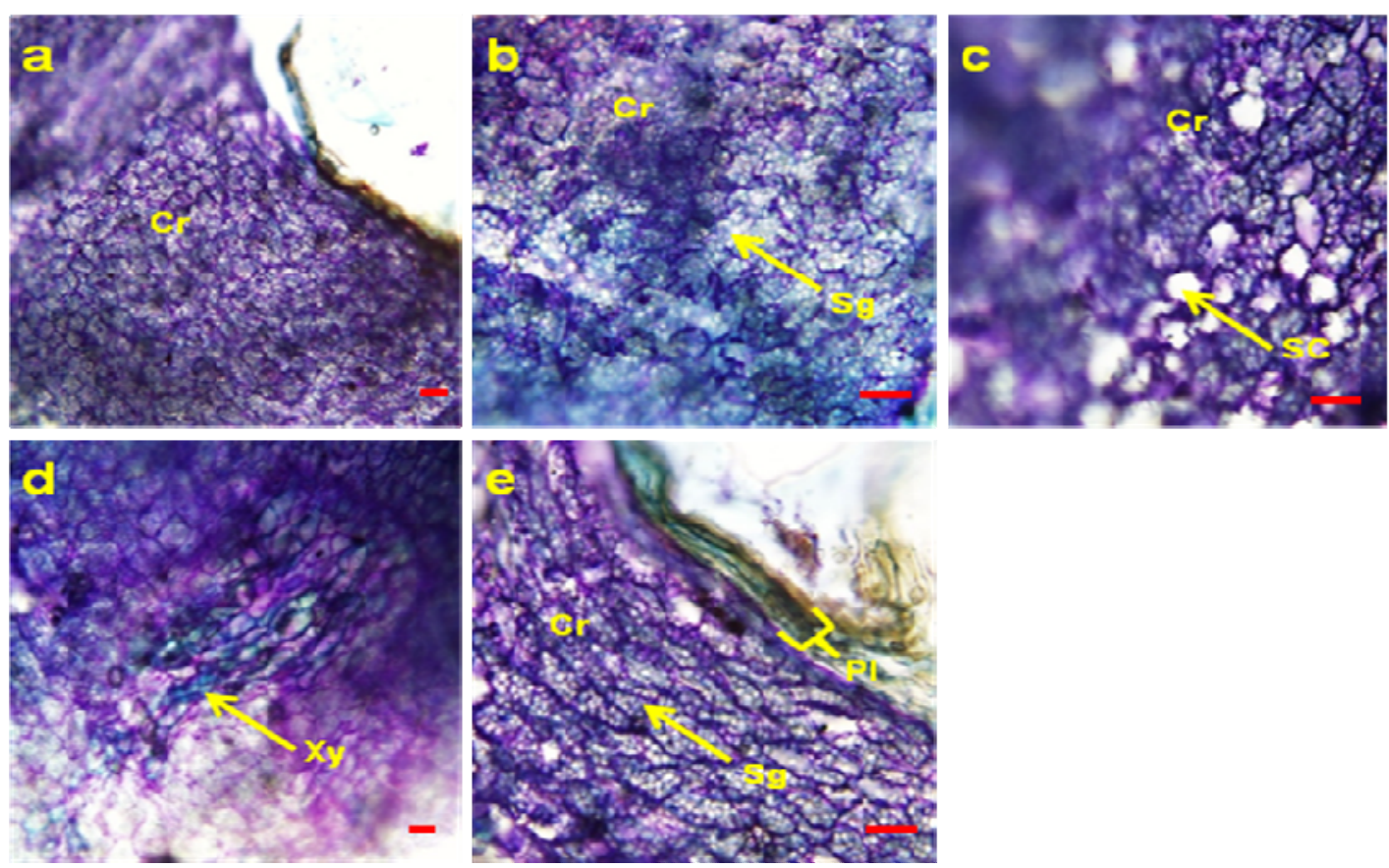

Figure 3. Cross sections of Corydalis ternate Nakai sample CT078

Magnification and scale bar length are 3a and 3d: x100, $100 \mu \mathrm{m}$; 3b, 3c and 3e: x200, $50 \mu \mathrm{m}$. Symbols: Cr, Cortex; Sg, Starch Granules; Xy, Xylem; Pl, Peridermal Layers; SC, Secretory Cells.
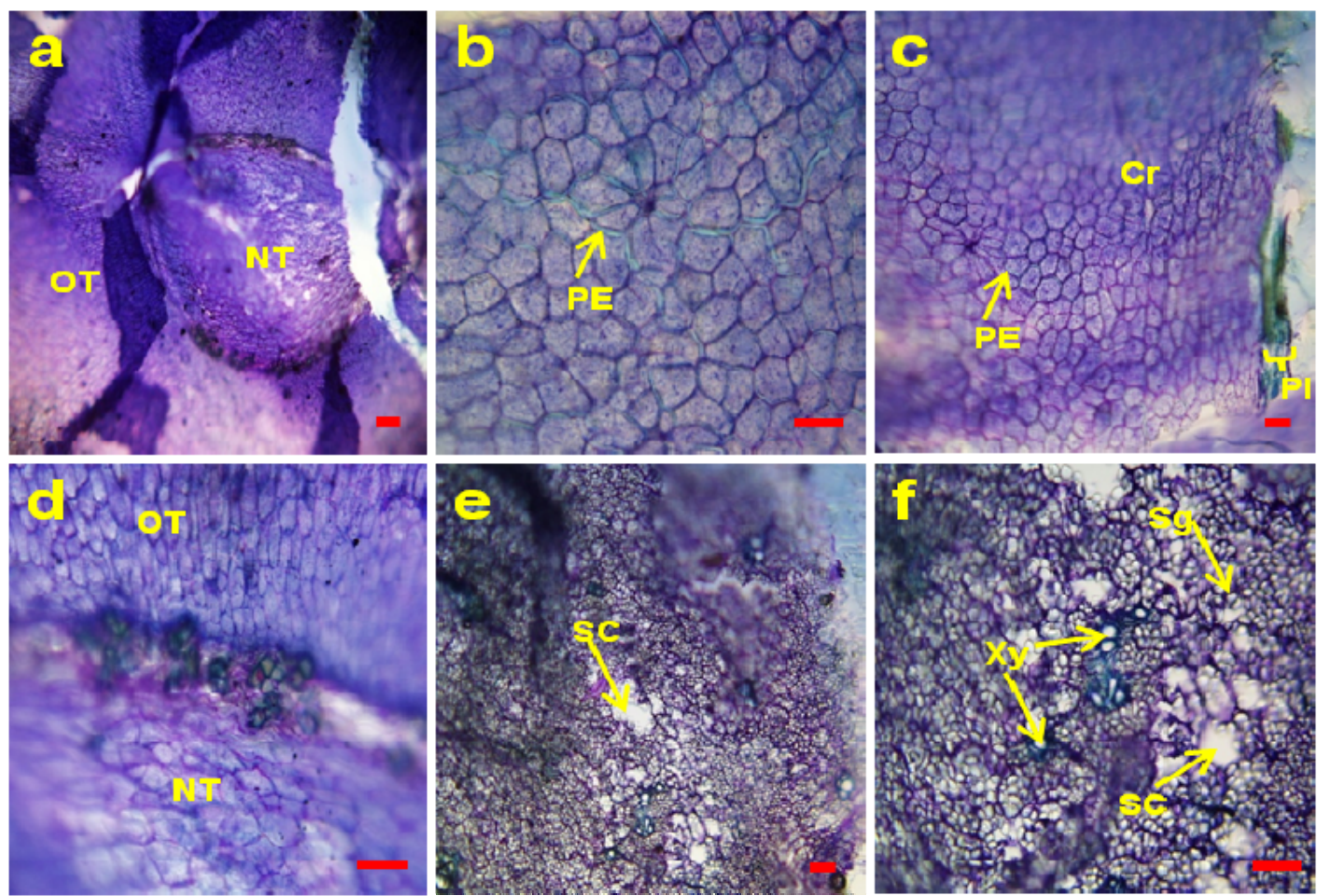

Figure 4. Cross sections of Corydalis ternate Nakai sample CT080

Magnification and scale bar length are 4a: x40, $25 \mu \mathrm{m}$; 4b, 4d and 4f: x200, $50 \mu \mathrm{m}$; 4c and 4e: x100, $100 \mu \mathrm{m}$. Symbols: OT, Old Tuber; NT, New Tuber; PE, Phloem conducting elements; Cr, Cortex; SC, Secretory Cells; Xy, Xylem; Sg, Starch Granules. 

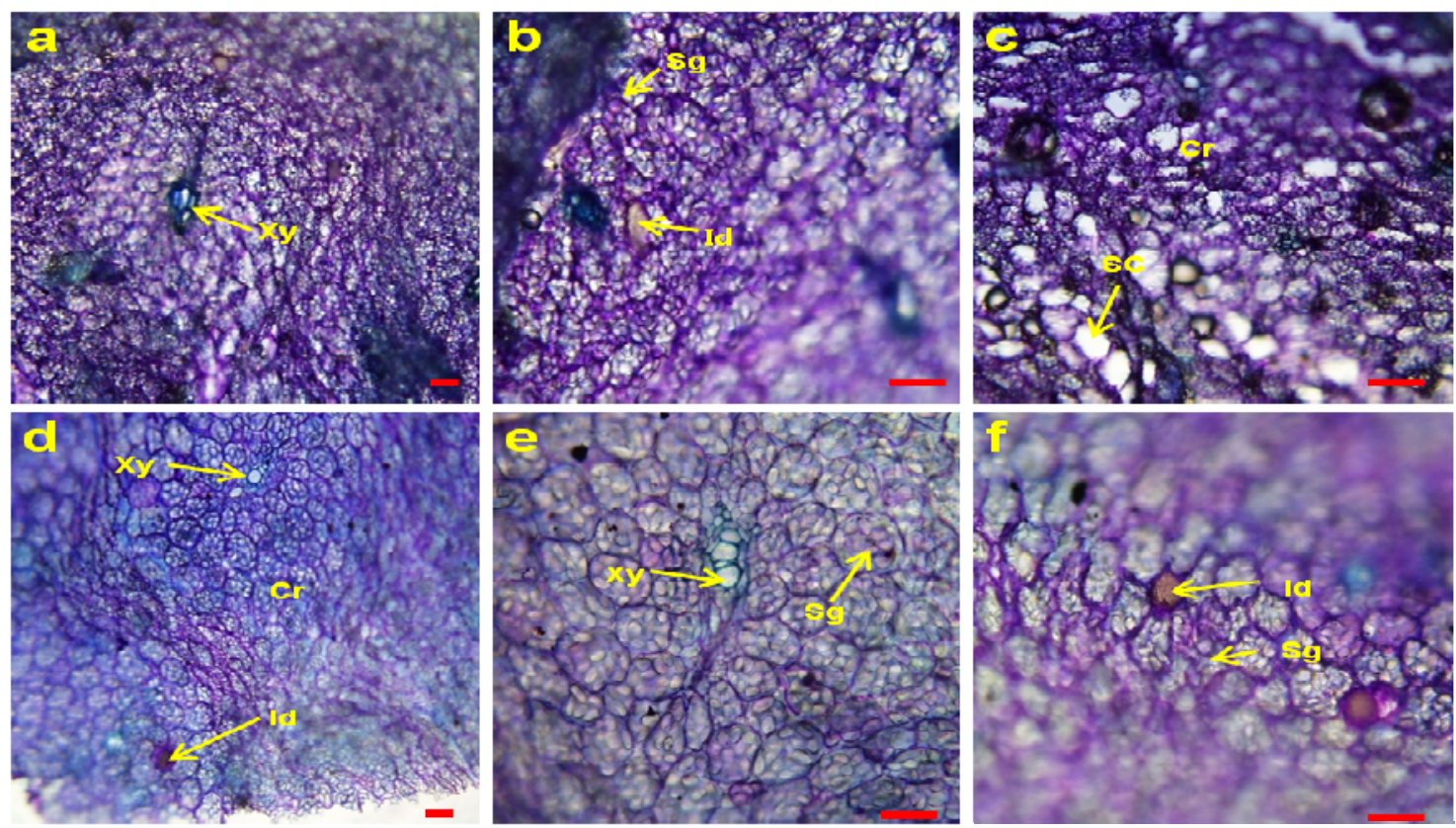

Figure 5. Cross sections of Dioscorea batatas Decaisne samples KYGW and KNJS. Sample, magnification and scale bar length are 5a: KYGW, x100, $100 \mu \mathrm{m}$; 5b and 5c: KYGW, x200, $50 \mu \mathrm{m}$; 5d: KNJS, x100, $100 \mu \mathrm{m}$; 5e and 5f: KNJS, x200, 50 mm. Symbols: Xy, Xylem; Sg, Starch Granules; Cr, Cortex; SC, Secretory Cells; Xy,

Xylem; Id, Idioblasts
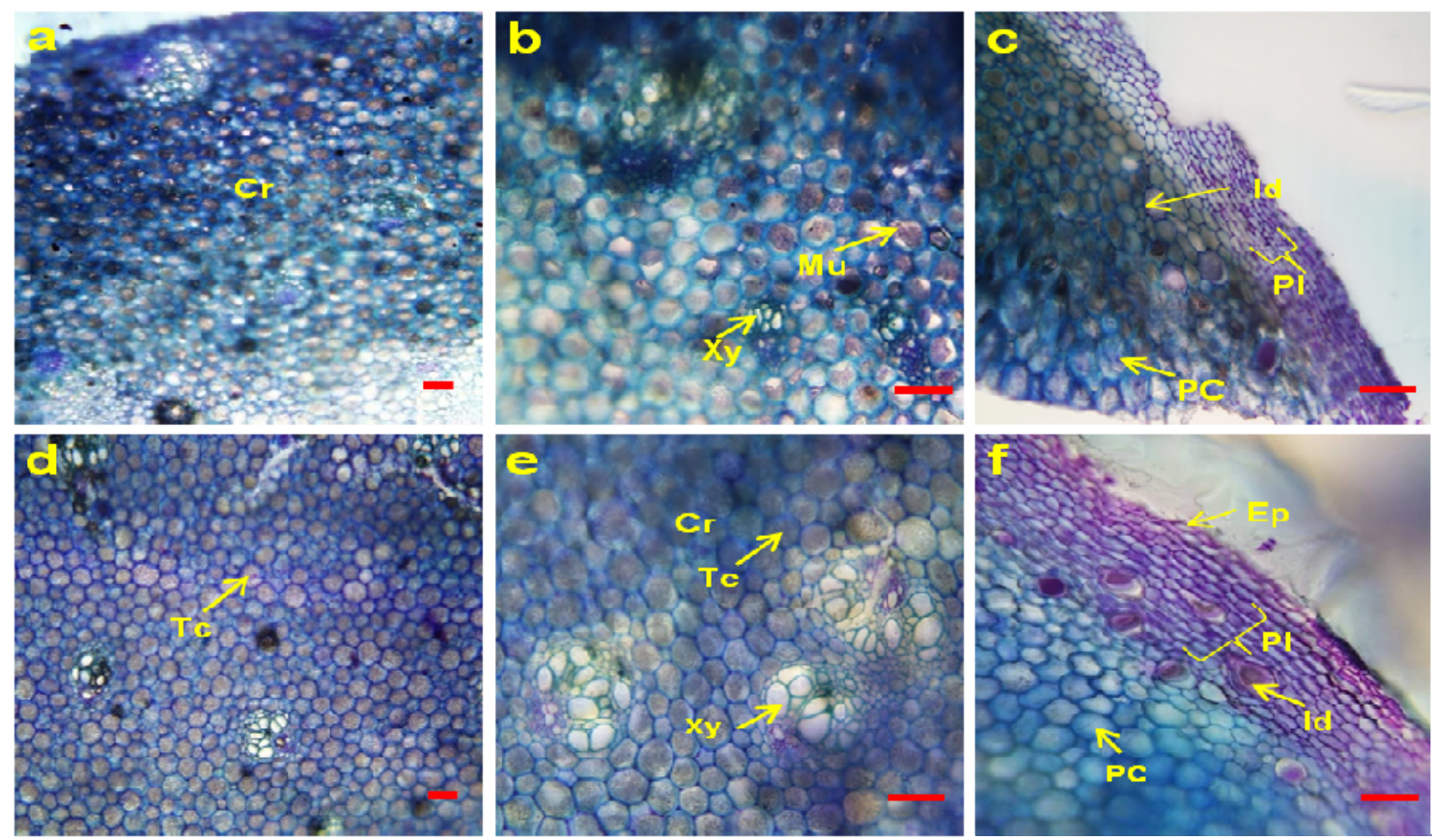

Figure 6. Cross sections of Dioscorea nipponnica Makino samples LY18P and LY026. Sample, magnification and scale bar length are 6a: LY18P, x100, $100 \mu \mathrm{m}$; 6b and 6c: x200, $50 \mu \mathrm{m}$; 6d: LY026, x100, $100 \mu \mathrm{m}$; 6e and 6f: LY026, x200, 50 m. Symbols: Cr, Cortex; Mu, Mucigel, Xy, Xylem; Id, Idioblasts; PC, Parenchyma Cells; Pl, Periderm Layers; Tc, Tannin Cells; Ep, Epidermis 


\subsection{Dioscorea batatas Decaisne}

The fundamental internal structure is composed of vascular bundles, parenchyma, and cork layers (Figure 5). The vascular bundle system is developed similarly to that of Corydalis sp., and it is distributed throughout the cortex layer (Figure 5). The storage parenchyma cells, which tend to occupy the whole cortex area, accumulate starch grains (Figures $5 \mathrm{~b}-5 \mathrm{c}$, and $5 \mathrm{f}$ ). These grains are relatively larger and more regular than those of Corydalis sp. (Figure 5f). In the cortex area, idioblasts occur and, inside those cells, raphides or mucilage are present (Figures 5b, 5d and 5f).

\subsection{Dioscorea nipponnica Makino}

The fundamental internal structure is composed of vascular bundles, parenchyma, and cork layers (Figure 6). The vascular bundle system is well developed compared to those of Corydalis sp. and Dioscorea batatas Decaisne, and is distributed throughout the cortex (Figures $6 \mathrm{~d}-6 \mathrm{f}$ ). The storage parenchyma cells, which occupy the whole cortex area, are roundish-shaped with angles (Figure 6). There are accumulations of tannins inside the parenchyma cells (Figures $6 \mathrm{~d}-6 \mathrm{e}$ ). Idioblasts are present in the borders between cortex and cork layers (Figures $6 \mathrm{c}$ and $6 \mathrm{f}$ ). The cork layers are distinct and they are developed with many layers (Figures $6 \mathrm{c}$ and 6f). They are strongly connected to the cortex area unlike the thinner and more breakable layers in Corydalis sp. and Dioscorea batatas Decaisne.

Table 1. Details of the herbal medicine samples used in this study. The voucher specimens are kept at NPRI (Natural Products Research Institute) at Seoul National University

\begin{tabular}{lll}
\hline Scientific Name & Sample number & Place purchased (China) \\
\hline Corydalis ternate Nakai & CT069 & JulKang \\
Corydalis ternate Nakai & CT072 & JulKang \\
Corydalis ternate Nakai & CT073 & Sumsuhhangjung \\
Corydalis ternate Nakai & CT075 & JulKang \\
Corydalis ternate Nakai & CT078 & JulKang \\
Corydalis ternate Nakai & CT080 & Shanshisung \\
Dioscorea batatas Decaisne & KNJS & HoBukSung \\
Dioscorea batatas Decaisne & KSHM & HoBukSung \\
Dioscorea batatas Decaisne & KYGW & HoBukSung \\
Dioscorea nipponnica Makino & LY026 & HukRyongKangSung \\
Dioscorea nipponnica Makino & LY18P & HukRyongKangSung \\
\hline
\end{tabular}

\section{Discussion}

In the current study distinct differences were seen between thin cross-sections of Corydalis and Dioscorea made from resin-embedded tuber samples. This demonstrates that anatomical characters have potential for the straightforward and easy identification of medicinal plant materials. Traditionally, tissue embedding was done using wax or Paraplast on fresh materials. However, there are significant advantages in tissue embedding of using hydrophilic resin rather than wax. First, hydrophilic resin does not have to be removed before treating the embedded specimen with any enzyme or staining solutions. This compares favorably with wax embedding, where the wax must be removed before further processing. This saves time and effort. Secondly, resin can be used for hardened materials after pre-treating the specimens with an alkali, such as ammonia, followed by dehydration.

When resin embedded herbal drug materials are to be cut on a microtome, the appropriate section thickness depends on the types of cells and tissues present. As explained by Carlquist (2001), when it is intended to observe wood anatomical characters on the cell surface of vessel elements, the section should not be too thin, in order to avoid accidently removing important characters. Staining the tissues using a metachromic dye, such as Toluidine Blue $\mathrm{O}$, should be considered for visualizing thickened or lignified cell walls or non-lignified internal cells, etc. Even though technology is evolving rapidly, scientists or researchers should focus on the specific scientific information required, and not be distracted into making thinner sections or more complicated staining 
simply because these are possible.

In conclusion, anatomical characters of medicinal plant materials can be a useful and supportive tool for determining authentic herbal drugs, particularly when accompanied by other taxonomic or systematic information including morphology and DNA sequences. Even though DNA barcoding is leading the identification world of herbal drugs currently, one approach cannot be the answer for all considering the importance of correcting failed quality control of worldwide usage of drugs.

\section{Acknowledgements}

The author thanks to Dr. Marin Shepherd for the critical reviews, comments, and his expertise.

\section{References}

Ahmad, M., Khan, M., Rashid, A. U., Zafar, M., Arshad, M., \& Sultana, S. (2009). Quality assurance of herbal drug valerian by chemotaxonomic markers. African Journal of Biotechnology, 8(6), 1148-1154. http://www.academicjournals.org/AJB

Blunden, G., Hardman, R., \& Hind, F. J. (1971). The comparative morphology and anatomy of Dioscorea sylvatica Eckl. from Natal and the Transvaal. Botanical Journal of Linnean Society, 64, 431-446. http:dx.doi.org/10.1111/j.1095-8339.1971.tb02156.x

Carlquist, S. (2001). Comparative wood anatomy; systematic, ecological, and Evolutionary aspects of Dicotyledon wood. Berlin: Springer-Verlag.

Dahanukar, S. A., Kulkarni, R., \& Rege, N. N. (2000). Pharmacology of medicinal plants and natural products. Indian Journal of Pharmacology, 32, S81-S118.

Endress, P. K., Baas, P., \& Gregory, M. (2000). Systematic plant morphology and anatomy - 50 years of progress. Taxon, 49(3), 401-434. http://dx.doi.org/10.2307/1224342

Ghosh, S., Ahire, M., Patil, S., Jabgunde, A., Dusane, M. B., Joshi, B. N., Pardesi, K.,...Chopade, B. A. (2012). Antidiabetic activity of Gnidia glauca and Dioscorea bulbifera: Potent amylase and glucosidase inhibitors. Evidence-Based Complementary and Alternative Medicine, 929051, 10. http:dx.doi.org/10.1155/2012/929051

Guo, X., Wang, X., Su, W., Zhang, G., \& Zhou, R. (2011). DNA barcodes for discriminating the medicinal plant Scutellaria baicalensis (Lamiaceae) and its adulterants. Biological and Pharmaceutical Bulletin, 34(8), 1198-1203. http://dx.doi.org/10.1248/bpb.34.1198

Harris, P., Ferguson, W. R., Roberton, A. M., McKenzie, R. J., \& White, J. B. (1992). Cell-wall histochemistry and anatomy of Taro (Colocasia esculenta). Australian Journal of Botany, 40, 207-222. http://dx.doi.org/10.1071/BT9920207

Henkes, H., Franz, M., Kendall, O., Monroe, J., Legaspi, A., LeDoux, J., \& Ceremuga, T. E. (2011). Evaluation of the anxiolytic properties of Tetrahydropalmatine, a Corydalis Yanhusuo compound, in the male Sprangue-Dawley rat. AANA Journal, 79(4), S75-S80. http://aana.com/aanajournalonline.aspx

Ji, H. Y., Liu, K. H., Jeong, J. H., Lee, D. Y., Shim, H. J., Son, M., \& Lee, H. S. (2012). Effect of a new prokinetic agent DA-9701 formulated with Corydalis tuber and Pharbitidis semen on Cytochrome P450 and UDP-Glucuronosyltransferase enzyme activities in human liver microsomes. Evidence-Based Complementary and Alternative Medicine, 650718, 8. http:dx.doi.org/10.1155/2012/650718

Keshavarzi, M., Tirtash, F. H., Ebrahimzadeh, F., \& Sheidaii, M. (2011). Comparative anatomy of the Fumaria (Papaveraceae) species in Iran. Phytologia Balcanica, 17(1), 79-87.

Khodorova, N. V., Miroslavov, E. A., Shavarda, A. L., Laberche, J. C., \& Boitel-Conti, M. (2010). Bud development in corydalis (Corydalis bracteata) requires low temperature: a study of developmental and carbohydrate changes. Annals of Botany, 105, 891-903. http:dx.doi.org/10.1093/aob/mcq076

Kim, E. K., Jeong, E. K., Han, S. B., Jung, J. H., \& Hong, J. (2011). HPLC separation of Isoquinoline alkaloids for quality control of Corydalis species. Bulletin of Korean Chemical Society, 32(10), 3597. http:dx.doi.org/10.5012/bkcs.2011.32.10.3597

Kiran, U., Khan, S., Mirza, K. J., Ram, M., \& Abdin, M. Z. (2010). SCAR markers: a potential tool for authentication of herbal drugs. Fitoterapia, 81, 969-976. http://dx.doi.org/10.1016/j.fitote.2010.08.002

Kundu, S. R. (2008). A compendium of Papaveraceae s.l. in Indian subcontinent: its distribution and endemism. International Journal of Botany, 4(3), 249-259. http://dx.doi.org/10.3923/ijb.2008.249.259

Li, P., \& Liu, H. J. (2011). Collection and identification of raw herbal materials, In W. J. H. Liu, (Ed.), 
Traditional Herbal Medicine Research Methods, pp. 27-79. John Wiley \& Sons, Inc. http://dx.doi.org/10.1002/9780470921340

Lidén, M. (1986). Synopsis of Fumarioideae (Papaveraceae) with a monograph of the tribe Fumarieae. Opera Botanica, 88, 1-133.

Lidén, M. (1995). A revision of Corydalis sect. Fumarioides Liden: Part-2. Rheedea, 5(1), 1-36.

Lux, A., Morita, S., Abe, J., \& Ito, K. (2005). An improved method for clearning and staining free-hand sections and whole-mount samples. Annals of Botany, 96, 989-996. http:dx.doi.org/10.1093/aob/mci266

Martin, F. W., \& Ortiz, S. (1963). Origin and anatomy of tubers of Dioscorea floribunda and D. spiculiflora. Botanical Gazette, 124(6), 416-421. http://dx.doi.org/10.1086/336228

McLean, R. C., (1916). The utilization of herbarium material. New Phytologist, 15(5/6), 103-107. http://dx.doi.org/10.1111/j.1469-8137.1916.tb07207.x

O’Brien, T. P., Feder, N., \& McCully, M. E. (1964). Polychromatic staining of plant cell walls by Toluidine Blue O. Protoplasma, Bd. LIX, H. 2, 367-373.

Sagare, A. P., Lee, Y. L., Lin, T. C., Chen, C. C., \& Tsay, H. S. (2000). Cytokinin-induced somatic embryogenesis and plant regeneration in Corydalis yan usuo (Fumariaceae) - a medicinal plant. Plant Science, 160, 139-147. http://dx.doi.org/10.1016/S0168-9452(00)00377-0

Sahoo, R. \& Swain, P. K. (2011). Standardization of Kutajaghana Vati: an Ayurvedic polyherbal formulation. International Journal of Pharmaceutical Sciences and Research, 2(10), 2686-2689. http://www.ijpsr.com

Serrano, R., \& Silva, D. S. (2010). Application of light and scanning electron microscopy in the identification of herbal medicines. In A. Méndez-Vilas, \& J. Díaz (Eds.), Microscopy: Science, Technology, Applications and Education, pp. 182-190.

Sultana, S., Khan, M. A., Ahmad, A. M., Bano, A., Zafar, M., \& Shinwari, Z. K. (2011). Authentication of herbal medicine Neem (Azandirachta indica A. Juiss.) by using taxonomic and pharmacognostic techniques. Pakistan Journal of Botany, 43, 141-150.

Tewtrakul, S., \& Itharat, A. (2006). Anti-allergic substances from the rhizomes of Dioscorea membranacea. Bioorganic \& Medicinal Chemistry, 14, 8707-8711. http://www.sciencedirect.com

Tsai, J. C., Tsai, S., \& Chang, W. C. (2004). Effect of ethanol extracts of thee Chinesemedicinal plants with anti-diarrheal properties on ion transport of the rat intestinal epithelia. Journal of Pharmacological Science, 94, 60-66. http://dx.doi.org/10.1254/jphs.94.60

Wang, Y., Liu, Y., Liu, Z., \& Yin, J. (2007). The quality control of the effective fraction from Dioscorea spongiosa. Asian Journal of Traditional Medicnes, 2(1), 12-18.

Wu, L., Ling, H., Li, L., Jiang, L., \& He, M. (2007). Beneficial effects of the extract from Corydalis yanhusuo in rats with heart failure following myocardial infarction. Journal of Pharmacy and Pharmacology, 59, 695-701. http:dx.doi.org/10.1211/jpp.59.5.0010

Xue, C. Y., \& Li, D. Z. (2011). Use of DNA barcode sensu lato to identify traditional Tibetan medicinal plant Gentianopsis paludosa (Gentianaceae). Journal of Systematics and Evolution, 49(3), 267-270. http:dx.doi.org/10.1111/j.1759-6831.2011.00127.x

Zafar, M., Khan, M. A., Ahmad, A., Sultana, S., Qureshi, R., \& Tareen, R. B. (2010). Authentification of misidentified crude herbal drugs marketed in Parkisan. J Med Plants Res, 4(15), 1584-1593. http://www.academicjournals.org/JMPR

Zhang, Y., Tang, L., An, X., Fu, E., \& Ma, C. (2009). Modification of cellulose and its application to extraction of diosgenin from Dioscorea zingiberensis C.H.Wright. Biochemical Engineering Journal, 47, 80-86. http://dx.doi.org/10.1016/j.bej.2009.07.006

Zhao, Z. (2010). Application of microscopic techniques for the authentication of herbal medicines. In A. Méndez-Vilas, \& J. Díaz (Eds.), Microscopy: Science, Technology, Applications and Education, pp. 803-812.

Zhao, Z., Xiao, E., Xiao, Y., \& Yuen, J. P. (2007). Quality assurance of Chinese herbal medicines (CHMs). Journal of Food and Drug Analysis, 15(4), 337-346.

Zhu, Y. L., Huang, W., Ni, J. R., Liu, W., \& Li, H. (2010). Production of diosgenin from Dioscorea zingiberensis tubers through enzymatic saccharification and microbial transformation. Applied Microbiology and Biotechnnology, 85, 1409-1416. http:dx.doi.org/10.1007/s00253-009-2200-8 